\title{
First expert elicitation of knowledge on drivers of emergence of the COVID-19 in pets
}

\author{
Claude Saegerman ${ }^{1}$, Juana Bianchini ${ }^{2}$, Véronique Renault ${ }^{3}$, Nadia $\operatorname{Haddad}^{4}$, and \\ Marie-France Humblet ${ }^{3}$ \\ ${ }^{1}$ Universtiy of Liege \\ ${ }^{2}$ University of Liège \\ ${ }^{3}$ University of Liege \\ ${ }^{4}$ Université Paris-Est, Ecole Nationale Vétérinaire d'Alfort
}

June 8,2020

\begin{abstract}
Infection with the Severe Acute Respiratory Syndrome Coronavirus 2 (SARS-CoV-2) induces the coronavirus infectious disease 19 (COVID-19). Its pandemic form in human population and its probable animal origin, along with recent case reports in pets, make drivers of emergence crucial in carnivore domestic pets, especially cats, dogs and ferrets. Few data are available in these species; we first listed forty-six possible drivers of emergence of COVID-19 in pets, regrouped in eight domains (i.e. pathogen/disease characteristics, spatial-temporal distance of outbreaks, ability to monitor, disease treatment and control, characteristics of pets, changes in climate conditions, wildlife interface, human activity, and economic and trade activities). Secondly, we developed a scoring system per driver, then elicited experts $(\mathrm{N}=33$ ) to: (i) allocate a score to each driver, (ii) weight the drivers scores within each domain and (iii) weight the different domains between them. Thirdly, an overall weighted score per driver was calculated; drivers were ranked in decreasing order. Fourthly, a regression tree analysis was used to group drivers with comparable likelihood to play a role in the emergence of COVID-19 in pets. Finally, the robustness of the expert elicitation was verified. Five drivers were ranked with the highest probability to play a key role in the emergence of COVID-19 in pets: availability and quality of diagnostic tools, human density close to pets, ability of preventive/control measures to avoid the disease introduction or spread in a country (except treatment, vaccination and reservoir(s) control), current species specificity of the disease causing agent and current knowledge on the pathogen. As scientific knowledge on the topic is scarce and still uncertain, expert elicitation of knowledge, in addition with clustering and sensitivity analyses, is of prime importance to prioritize future studies, starting from the top five drivers. The present methodology is applicable to other emerging pet diseases.
\end{abstract}

\section{Introduction}

At the end of December 2019, a cluster of undiagnosed human pneumonia cases, centred on the city of Wuhan (Hubei region), China, was reported (Huang, 2020). These cases were all related to a seafood and live animal (including wild animals) market (Xu et al., 2020). They presented clinical and epidemiological characteristics compatible with the Severe Acute Respiratory Syndrome (SARS) (ECDC, 2020). The etiologic agent was identified either directly from patient samples, or from virus cultures grown from patients hospitalised with pneumonia in Wuhan, using high-throughput sequencing. This agent was identified as an unknown $\beta$-coronavirus genetically close to SARS-CoV and named SARS-Cov-2 (Coronavirus Study Group of the International Committee for the Taxonomy of Viruses, 2020). The associated disease was named 'COVID-19', for Coronavirus disease-2019 (WHO, 2020a). Genetic proximity analyses with known sequences of other coronaviruses indicated that this virus originated in the animal world, i.e. from chiropterans, considered as 
an animal reservoir (bats), with possible passage through an intermediate host which was initially suspected to be the pangolin (Liu et al., 2020).

SARS-CoV-2 is the seventh coronavirus known to infect humans, and a zoonotic virus such as SARS-CoV and MERS-CoV (Mackenzie \& Smith, 2020) (Appendix S1 ). Direct contact, rather than airborne spread, seems to be the main transmission route for SARS-Cov-2 according to contact-tracing studies (Bi et al., 2020; Burke et al., 2020). Evidence indicates that SARS-CoV-2 is transmitted from human-to-human by infectious droplets, i.e. particles $>5-10 \mu \mathrm{m}$ in diameter (Federation of European Heating, Ventilation and Air Conditioning Associations, 2020). Potential airborne transmission (by droplet nuclei, which are generally considered to be particles $<5 \mu \mathrm{m}$ ) was evidenced by past studies for SARS-CoV-1 (Booth et al., 2005; Yu et al., 2014; Xiao et al., 2017) and more recently for both SARS-Cov-1 and SARS-Cov-2 in experimental conditions (van Doremalen et al., 2020). Additionally, faeco-oral (Wang et al., 2020; Cai et al., 2020; Wu et al., 2020; Woelfel at al., 2020; WHO, 2020b) and ocular (Dockery et al., 2020) transmission should also be considered.

Due to the above-mentioned transmission characteristics, the SARS-Cov-2 spread very quickly across China and worldwide since its first appearance (Wu and McGoogan, 2020). As of June 7, 2020, a total of 213 countries or territories have been affected by COVID-19 worldwide, with approximatively 7 million human cases (including 400,000 deaths) (https://www.worldometers.info/coronavirus/). The transmission dynamic of a disease is generally estimated by the calculation of the basic reproductive number, the so-called R0. In absence of control measures, the $\mathrm{R} 0$ is the number of individuals that become infected after the arrival of a primary infected individual in a fully susceptible (naive) population. During the COVID-19 pandemic, and based on 21 estimates, the R0 was between 1.9 and 6.5, including 13 estimates with a R0 between 2 and 3 (Park et al., 2020). This R0 was generally higher than MERS-Cov (Park et al., 2018) and pandemic influenza (Biggerstaff et al., 2014) but of similar magnitude to the previous SARS-CoV (Riley et al., 2003; Lipsitch et al., 2003), indicating a risk of global spread (Riou \& Althaus, 2020). However, the R0 is strongly influenced by mitigation measures (mainly effective physical distancing, quarantine and contact tracing) and needs to be less than one to stop the disease spread (Breban et al., 2013).

Recently, there have been reported cases in canids (dogs) and felids (cats, tigers) with possible high seroconversion (e.g. Zhang et al., 2020; Almendros, 2020; Almendros \& Gascoigne, 2020; American Veterinary Medical Association. 2020). Furthermore, recent experimental infections indicate a particular susceptibility of bats, cats and ferrets (Sit et al., 2020; Young-Il et al., 2020; Beer et al., 2020). In April 2020, farmed minks also tested positive to the virus in the Netherlands (Oreshkova et la., 2020).

Despite the few cases reported (until now reporting of animal COVID-19 is not mandatory in many countries), in comparison with the scale of infection in the human population, these observations in animals have provoked some violent reactions towards dogs and cats such as the panic abandonment of them (Qiao et al., 2020; Leroy et al., 2020).

The pandemic form of COVID-19 in human population and its probable animal origin and the recent serial of reported cases in pets, poses the question of what are the drivers of COVID-19 emergence in carnivore domestic pets, specifically cats, dogs and ferrets, as they are close companions to humans and the main pet in the household. Currently there are no published articles regarding the drivers of disease emergence in animals, with the exception of the recent study in livestock animals (Bianchini et al., 2020).

Indeed, the aim of this study was to list, rank and cluster drivers of COVID-19 emergence in pets, using elicitation of experts' knowledge on each driver and on the relative importance between drivers, in a specific domain of interest, and between these domains.

\section{Materials and methods}

\section{Species of pets included}

The objective was to prioritize the drivers of COVID-19 in pets. Using the following algorithms ((COVID-19) AND ((2019) OR (2020))), and ((COVID-19) AND (Pets)) search strings were conducted in PubMED (US 
National Library of Medicine, National Institutes of Health) and ProMED-mail (Program for Monitoring Emerging Diseases of the International Society for Infectious Diseases). The results of the search showed that cats, dogs and ferrets were the pets with most mentions in the articles, thus here the question was drivers for the emergence of COVID-19 in these species of pets. There was a big difference in the ratio between articles exclusively on "COVID-19 and pets" and "COVID-19 without pets" (Figure 1 ). The ratios were 0.00048 and 0.134 for PubMED and ProMED-mail, respectively at May 21, 2020.

\section{Questionnaire design}

To determine which are the main drivers of COVID-19 emergence in pets, a questionnaire was used. A driver was defined as a factor that has the potential to directly or indirectly precipitate ('drive') or lead to the emergence of COVID-19 in carnivore domestic pets. A former questionnaire made to rank re-emergence of animal diseases based on drivers (Bianchini et al., 2020) was modified and adjusted for COVID-19 in pets. For this, specific drivers of COVID-19 were identified by searching through the available scientific literature and discussion with experts from academia, government agencies and international bodies. These were then added into the questionnaire, or some other drivers were deleted from it as they were not considered pertinent. Finally, a total of forty-six drivers were established and classified in eight different domains (Table 1 ). The domains (D) were: (D1) pathogen/disease characteristics (N 9 drivers); (D2) distance of outbreaks (spatialtemporal scales) ( $\mathrm{N}=3$ drivers); (D3) ability to monitor, treat and control the disease ( $\mathrm{N}=7$ drivers); (D4) characteristics of pets ( $\mathrm{N}=7$ drivers); (D5) changes in climate conditions ( $\mathrm{N}=3$ drivers); (D6) wildlife interface ( $\mathrm{N}=6$ drivers); (D7) human activity $(\mathrm{N}=6$ drivers); and (D8) economic and trade activities ( $\mathrm{N}$ $=5$ drivers).

These were formatted in an Excel@ (Microsoft, Redmond, WA, USA, 2013) file with one spreadsheet per domain, each domain with the respective drivers. Each driver had a score with its definition, which could range from 0 to 4 or 1 to 4 and a cell to be given the intra driver weight point. A last spread sheet was added, in which the 8 domains were listed, with a cell to be given the inter-domain weight (Appendix S2)

\section{Expert elicitation on drivers used to assess the emergence of COVID-19 in pets}

An expert elicitation of knowledge was conducted, which consisted in gathering the opinion of people with recognized scientific expertise and/or experience in the field of COVID-19 in pets (Appendix S3 ). For guidance purposes, an explanatory letter accompanied the questionnaire that each expert had to fill out (Appendix S4 ). The questionnaire was prepared as an Excel file based onAppendix S2 .

Each expert was contacted personally and responded individually to the questionnaire. Data generated by the elicitation were based on the individual values provided by experts in order to capture the degree of variability of expert knowledge. The elicitation was performed from 24/04/20 to 15/05/20.

\section{Scoring and weighting system}

The elicited experts were asked to provide three types of information. First, they were asked to score the driver (as established inAppendix S2 ). For each driver, higher is the score more the driver have a chance to contribute to the emergence of the COVID-19 in pets. Note that uncertainty score was not asked due to lack of evidence-based data at this stage regarding the COVID-19 in pets. Secondly, experts were requested to weight each driver within a specific domain (intra-domain weight). This relative weight was determined using the Las Vegas technique (Gore, 1987). Briefly, experts were given a number of points to be distributed between the drivers according to their importance in the specific domain. If all the drivers of a specific domain would have been considered as equivalent by experts, each of them would have received the same number of points. Lastly, the relative importance of each domain was subsequently weighted by experts (inter-domain weight).

\section{Calculation of an overall weighted score for each driver and ranking process}

To obtain the overall score per driver, an aggregation method that combined the two types of weighting 
(i.e. the intra and inter-domain) was used. First, the driver score (coefficients attributed by experts) was standardised by dividing it by the number of possibilities. Indeed, some drivers were allocated coefficients from 0 to 4 (5 possibilities) and others from 1 to 4 (4 possibilities). Afterwards, this standardised score was multiplied by the intra-domain weight and the inter-domain weight, as given by the expert. These results allowed obtaining an overall weighted score for each driver and per expert:

$$
\mathrm{OWS}_{\mathrm{Dr} i}=\mathrm{SDr}_{\mathrm{i}} \times \mathrm{WDr}_{\mathrm{i}} \times \mathrm{WDo}_{\mathrm{j}}[\text { Equation 1] }
$$

In this formula, $\mathrm{OWS}_{\mathrm{Dr} i}=$ overall weighted score for a specific driver ${ }_{i} ; \mathrm{SDr}_{\mathrm{i}}=$ standardized score for a specific driver $_{i} ; \mathrm{WDr}_{\mathrm{i}}=$ intra-domain weight for a specific driver $_{i} ; \mathrm{WDo}_{\mathrm{j}}=$ inter-domain weight for a

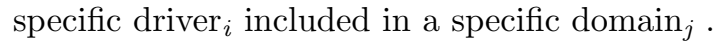

Furthermore, all drivers were ranked based on the median overall weighted score obtained for each driver and taking into account the answers of all the experts, which answered the questionnaire.

The statistical difference of the median, depending of the specific driver or the group of drivers considered, was assessed through a non-parametric Kruskal-Wallis equality-of-populations rank test (State SE 14.2; StataCorp, College Station, Texas, USA).

\section{Cluster analysis}

A cluster analysis was done using a regression tree analysis (Salford Predictive Modeler ${ }^{\circledR}$, Version 8.2, Salford Systems, San Diego, California, USA). The median overall weighted score (median $\mathrm{OWS}_{\operatorname{Dr} i}$ ) being a continuous variable, the aim was to obtain groups of drivers with minimal within-group variance, with comparable likelihood to play a role in the emergence of COVID-19 in pets (e.g. very high importance, high importance, moderate importance and low importance). In addition, the statistical difference between medians after grouping drivers in clusters was assessed using a non-parametric Kruskal-Wallis equality-ofpopulations rank test. Indeed, each driver is characterised by a median (based on all experts' answers), then drivers are grouped. The test allows highlighting potential significant differences between groups, in terms of driver medians, after clustering.

\section{Sensitivity analysis to test the robustness of the expert elicitation}

In order to identify whether the ranking of COVID-19 drivers of emergence in pets was influenced or not by the choice of experts, a sensitivity analysis was performed.

First, we started by ranking the drivers using the obtained median $\mathrm{OWS}_{\mathrm{Dr} i}$. Second, an expert was not considered in the analysis and the ranking of the drivers was done using the same methodology previously described. This was done expert by expert. Third, we counted how many changes in the ranking were observed, for each driver, only considering changes of more than five ranks (i.e. around $10 \%$ of all drivers). A graph was created to visualize any modification of rank induced by the withdrawal of a given expert.

\section{Results}

\section{Response rate and field of expertise mobilised by the experts}

From the 46 professionals regarded as having scientific knowledge and/or proven field knowledge or experience on COVID-19 in pets that were contacted, 33 of them agreed to participate (77\% response rate) with a balance between male $(\mathrm{N}=18)$ and female $(\mathrm{N}=14)$. The field of expertise were summarised in Appendix S3 .

\section{Estimating the overall weighted score and ranking of drivers of COVID-19 emergence in pets}

According to the non-parametric Kruskal-Wallis test, the medians of the weight between domains of drivers are not equal (Chi-squared test $=114$ with 7 d.f. and $\alpha=0.05 ; P$-value $=0.0001)($ Figure 2$)$.

Moreover, according to the non-parametric Kruskal-Wallis test, the medians of the overall weighted scores for the different drivers are not equal (Chi-squared test $=772$ with 45 d.f. and $\alpha=0.05 ; P$-value $=$ 0.0001). Five of them were ranked as having the highest probability to play a key role in the emergence of COVID-19 in pets. These were in decreasing order: "availability and quality of diagnostic tools", "human 
density close to pets", "ability of preventive/control measures to stop the disease from entering the country or spreading (except for treatment, vaccination and reservoir(s) control)", "current species specificity of the disease causing agent" and "current knowledge on the pathogen" (Figure 3 ).

\section{Cluster analysis}

The regression tree analysis determined four clusters (Figure 4 ) that were significantly different (nonparametric Kruskal-Wallis equality-of-populations rank test; Chi-squared test $=38.7$ with 3 d.f. and $\alpha=$ $0.05 ; P$-value $=0.0001$ ). These four clusters were classified as, respectively "low importance" with 22 drivers, "moderate importance" with 14 drivers, high importance and very high importance each with 5 drivers each. The drivers in the "very high importance" node are the five highest ranked, mentioned in the previous paragraph.

\section{Sensitivity analysis of the impact of experts on the final ranking of COVID-19 drivers of emergence in pets}

The result of the sensitivity analysis indicated that ignoring any expert had only a limited effect on the ranking of drivers (Figure 5 ). However, a change of maximum six ranks was observed for the driver D1-8 (i.e. mode of transmission of the SARS-Cov-2) when four experts were ignored (represented by the number of crosses inFigure 5 ). In the overall ranking, this driver ranks in the middle. In addition, they are no or very few changes of ranks in the extremes (first and last drivers) of the initial ranking.

\section{Discussion}

According to this expert elicitation of knowledge, forty-six drivers of COVID-19 emergence in carnivore domestic pets (cats, dogs and ferrets) were ranked and aggregated into four homogenous groups. The first group of drivers categorised in the "very high importance" node, will be further discussed and it includes in decreasing order: availability and quality of diagnostic tools, human density close to pets, ability of preventive/control measures to stop the disease from entering the country or spreading (except for treatment, vaccination and reservoir(s) control), current species specificity of the disease causing agent and current knowledge on the pathogen. The sensitivity analysis indicated a limited effect of the experts involved in the elicitation, which shows that there is an acceptable robustness of the elicitation.

Considering as the highest driver of emergence of COVID-19 in pets, the availability and quality of diagnostic tools of COVID-19 infection in pets seemed to be critical (driver: D3-4). Currently, diagnostic tests are only available in specialized laboratories, e.g. polymerase chain reaction assay $(\mathrm{PCR})$, virus neutralisation assay (VNT), microsphere immunoassay (MIT), enzyme-linked immunosorbent assay (ELISA) (e.g. Zhang et al., 2020; Sailleau et al., 2020). Indeed, the capacity to confirm a suspected case is very limited. Some of these laboratories are also often prioritise to diagnose human cases of COVID-19, and not animal cases. The PCR assay allows the specific detection of SARS-Cov-2 RNA and helps finding the source of infection (e.g. phylogenetic tree). Addition of serological assays would allow differentiating between environmental contamination (PCR positive and serological test negative) and (transient) infection (PCR positive or negative depending of the stage of infection but serological test positive) in pets. Another aspect is the usefulness to collect and share the different information on pets at national and international levels to be able to assess properly the true status of pets in the transmission of the COVID-19, based on evidence, and to guide both risk management and risk communication under the One Health approach. This is particularly important to avoid any inadequate behaviour of owners like panic abandonment of household pets. Recently, the OIE published guidelines for pet sampling (based on epidemiological contexts, e.g. close contact with a suspected or confirmed SARS-CoV-2-infected patient, or animal exposed to a known high-risk environment, and clinical presentation, e.g. clinical signs suggestive of SARS-Cov-2 infection), testing (based on validated tests, suitable for its intended use, which is essential when testing different species due to possible variation in sensitivity and specificity), and reporting of SARS-Cov-2 in animals (OIE, 2020). In addition, according to the Terrestrial Animal Health Code, the notification of COVID-19 cases in animals should be reported to the OIE as an emerging disease through the World Animal Health Information System (WAHIS). 
The second most important driver was the human density close to pets (driver: D4-5). Indeed, humans have a strong effect on the introduction and spread of COVID-19 in pets. In Europe, at least 80 million households own at least one pet and the number of cats and dogs accounts for 103,828,000 and 85,184,000 heads, respectively. Around $25 \%$ of owners have at least one cat and $25 \%$, one pet (FEDIAF, 2019). This percentage is not homogeneous and large disparities exists depending of the region for a same country. As an example, this percentage is higher in the Southern part (around 33\% - more rural part) than in the Northern part (around 25\%) of Belgium. No data on households with ferret are available at national level despite its important experimental susceptibility regarding the SARA-Cov-2. However, more studies are needed to assess properly the human density close to pets in Europe, in particular species by species.

The third most important driver was the ability of preventive/control measures to stop the disease from entering the country or spreading (containment of the pandemic), except for treatment, vaccination and reservoir(s) control (driver: D3-1). Most experts mentioned the current lack of sanitary certification, incomplete traceability of animals, ineffective disinfection measures, incomplete restriction of contacts between pets and wild animals and ineffective biosecurity measures. The main present interest of this driver is that the more human infection will be limited, the more risks of pet infections by humans will be reduced. Moreover reporting of all confirmed COVID-19 infections of pets should be mandatory. Additionally, several initiatives need to be emphasised to improve the situation like the OIE guidelines for sampling, testing and reporting of SARS-Cov-2 in animals (OIE, 2020) and several pet management recommendations given by national (e.g. Académie Nationale de Médecine, 2020) or international (e.g. American Veterinary Medical Association. 2020) expert committees. More evidence-base information and protocols should be stimulated and shared.

The fourth most important driver was the current species specificity of the disease-causing agent (driver: D1-2). The number of pet species susceptible to SARS-Cov-2 is not yet completely elucidated (OIE, 2020) but according to field studies, animals such as cats, dogs, ferrets, tigers, minks and small rodents have been identified as susceptible (e.g. Zhang et al., 2020; Almendros, 2020; Almendros \& Gascoigne, 2020; American Veterinary Medical Association. 2020; van der Poel W., 2020).

In addition, experimental infections indicate a particular susceptibility of bats, cats and ferrets (Sit et al., 2020; Young-Il et al., 2020; Beer et al., 2020). The species specificity is related to the aptitude of the coronavirus to interact with the host receptor $(\mathrm{Li}, 2012)$. The receptor recognition mechanism of the SARSCov-2 regulates, in great part, its infectivity, pathogenesis and host range (Shang et al., 2020). SARS-CoV-2, SARS-CoV and RaTG13 (a bat coronavirus that is closely related to SARS-CoV-2) recognize the same receptor angiotensin-converting enzyme 2 (ACE2) in humans ( $\mathrm{Li}$ et al., 2003; Li et al., 2005; Shang et al., 2020). However, some specific structural characteristics of the receptor-binding domain (RBD) of SARS-Cov2 spike protein increase its ACE2-binding affinity (Shang et al., 2020). Differences among the three cited viruses in ACE2 recognition could contribute to explain their differential potentials for animal-to-human transmission, which appears more limited for SARS-CoV-2 \& SARS-CoV1 than for MERS-CoV, but also for human-to-human transmission (conversely more reduced for MERS-CoV than for SARS-CoV-2 \& SARSCoV1), and eventually for human-to-animal transmission, which is supposed to occur for SARS-CoV2 only. With the exception of few works (Xu et al., 2009; Bao et al., 2020), more studies are needed to investigate the ACE2 receptor in various animal species. In addition, other unknown important factors conditioning animal-to-human and/or human-to-animal could deserve to be characterized (McNamara et al., 2020).

The fifth most important driver was the current knowledge on the pathogen (driver: D1-1). Scientific knowledge on the SARS-Cov2 is limited so far because it is still under characterization, even if it belongs to a well-known and studied family of pathogens. The pathogen includes multiple variants that are not characterised yet. A recent study on SARS-CoV-2 sequences $(\mathrm{N}=95)$, from the first 3 months of the pandemic, reveals a beginning of diversification and phylogenetic clustering due to base substitutions and deletions in the genomes. This preliminary result should permit tracing of source infection but such variability could induce differences in virulence or antigenicity, with possible consequence in virulence (implication on population immunity) or antigenicity (implication on the diagnostic) (Kaden, 2020). This variability could also 
contribute to a change in species barriers, which could contribute to variants more adapted to pets and potentially to retransmission to humans (or to reduced zoonotic potential for these variants). More global studies are needed with good sharing of information to ensure progress in tracing of source infection and the development of accurate vaccines and diagnostic assays.

The methodology that was develop in this paper should be extended to a wide number of other diseases of pets, starting from cats and dogs, the two main species in households (FEDIAF, 2019). In addition, this expert elicitation of knowledge should be refined in the future (some months) when more evidence data will be available. In this case, addition of an uncertainty rate should be recommended during elicitation.

\section{CONCLUSION}

The nature of SARS-Cov-2, its wide distribution and the susceptibility of some animal species to infection mean that close contact between humans and animals can probably induce infections in animals. Since scientific knowledge on COVID-19 drivers of emergence is scarce and associated uncertainty high, expert elicitation of knowledge, in addition with clustering and sensitivity analyses, is of prime importance to prioritize future studies, starting from the top five ranked drivers. The present methodology can also be applied to other pet diseases in pets in order to anticipate decision-making and awareness.

\section{ACKNOWLEDGEMENTS}

The authors thank all experts who participated to this study. Their names can be found in Appendix S3 . Special thanks to J.P. Ganière for its critical reading of the questionnaire before its spread.

\section{Conflict of interest statement}

The authors declare no conflict of interest.

\section{Data availability statement}

The data that support the findings of this study are available from the corresponding author upon reasonable request.

\section{Ethical approval}

Due to the nature of the study and the low risk posed to participants, formal approval from an Ethics Committee was not a requirement at the time of the study.

\section{ORCID}

Claude Saegermanhttps://orcid.org/0000-0001-9087-7436

Véronique Renaulthttps://orcid.org/0000-0003-2529-3965

Nadia Haddadhttps://orcid.org/0000-0001-7079-8319

Marie-France Humblethttps://orcid.org/0000-0003-4069-9402

\section{ReferenceS}

Acha, P.N., Szyfres, B. (2005). Preface of the first English edition. In: Zoonoses and communicable diseases common to man and animals, Volume 1: bacteriosis and mycoses [in

French]. 3rd edition. Paris: OIE; 2005. p. ix.

Aegerter, J., Fouracre, D., Smith, G.C. (2017). A first estimate of the structure and density of the populations of pet cats and dogs across Great Britain. PLoS One. 12(4): e0174709. doi: 10.1371/journal.pone.0174709

Almendros, A. (2020). Can companion animals become infected with Covid-19? Vet Rec. 186(12), 388-389. doi: $10.1136 /$ vr.m1194. 
Almendros, A, Gascoigne, E. (2020). Can companion animals become infected with Covid-19? Vet Rec. 186(13), 419-420. doi: 10.1136/vr.m1322.

American Veterinary Medical Association. 2020. SARS-CoV-2 in animals, including pets. Available at:https://www.avma.org/resources-tools/animal-health-and-welfare/covid-19/sars-cov-2-animals-includingpets(Acceded at 27 May 2020).

Beer M. (2020) COVID-19: Experimental infection of fruit bats, ferrets, pigs and chicken with SARS-CoV-2 at Friedrich-Loeffler-Institut. ProMed-mail. Archive Number: 20200407.7196506.

Bi, Q., Wu Y, Mei S, Ye C, Zou X, Zhang Z, Liu X., Wei L., Truelove S.A., Zhang T., Gao W., Cheng C., Tang X., Wu X., Wu Y., Sun B., Huang S., Sun Y., Zhang J., Ma T., Lessler J., Feng T. (2020). Epidemiology and Transmission of COVID-19 in 391 Cases and 1286 of Their Close Contacts in Shenzhen, China: A Retrospective Cohort Study. Lancet Infect Dis S1473-3099(20), 30287-30285. doi: 10.1016/S14733099(20)30287-5.

Bianchini, J., Humblet, M.F., Cargnel, M., Van der Stede, Y., Koenen, F., de Clercq, K., Saegerman, C. (2020). Prioritization of livestock transboundary diseases in Belgium using a multicriteria decision analysis tool based on drivers of emergence. Transbound Emerg Dis. 67(1), 344-376. doi: 10.1111/tbed.13356.

Biggerstaff, M., Cauchemez, S., Reed, C., Gambhir, M., Finelli, F. (2014). Estimates of the Reproduction Number for Seasonal, Pandemic, and Zoonotic Influenza: A Systematic Review of the Literature. BMC Infect Dis. 14, 480. doi: 10.1186/1471-2334-14-480.

Bao, L., Deng, W., Huang, B., Gao, H., Liu, Ren, L., Wei, Q., Yu, P. et al. (2020). The pathogenicity of SARS-CoV-2 in hACE2 transgenic mice. Nature https://doi.org/10.1038/s41586-020-2312-y (2020).

Booth, T.F., Kournikakis, B., Bastien, N., Ho, J., Kobasa, D., Stadnyk, L., Spence, M., Paton, S., Henry, B., Mederski, B., White, D., Low, D.E., McGeer, A., Simor, A., Vearncombe, M., Downey, J., Jamieson, F.B., Tang, P., Plummer, F. (2005). Detection of Airborne Severe Acute Respiratory Syndrome (SARS) Coronavirus and Environmental Contamination in SARS Outbreak Units. J Infect Dis.191(9), 1472-1477. doi: $10.1086 / 429634$.

Breban, R., Riou, J, Fontanet, A. (2013). Interhuman Transmissibility of Middle East Respiratory Syndrome Coronavirus: Estimation of Pandemic Risk. Lancet 382(9893), 694-699. doi: 10.1016/S0140-6736(13)61492-0.

Burke, R.M., Midgley, C.M., Dratch, A., Fenstersheib, M., Haupt, T., Holshue, M., Ghinai, I., Jarashow, M.C., Lo, J., McPherson, T.D., Rudman, S., Scott, S., Hall, A.J., Fry, A.M., Rolfes, M.A. (2020). Active Monitoring of Persons Exposed to Patients with Confirmed COVID-19 - United States, January-February 2020. MMWR Morb Mortal Wkly Rep. 69(9), 245-246. doi: 10.15585/mmwr.mm6909e1.

Cai, J., Xu, J., Lin, D., Yang, Z., Xu, L., Qu, Z., Zhang, Y., Zhang, H., Jia, R., Liu, P., Wang, X., Ge, Y., Xia, A., Tian, H., Chang, H., Wang, C., Li, J., Wang, J., Zeng, M. (2020). A Case Series of children with 2019 novel coronavirus infection: clinical and epidemiological features. Clin Infect Dis. ciaa198. doi: $10.1093 / \mathrm{cid} / \mathrm{ciaa} 198$.

Coronaviridae Study Group of the International Committee on Taxonomy of Viruses. (2020). The species Severe acute respiratory syndrome-related coronavirus: classifying 2019-nCoV and naming it SARS-CoV-2. Nat Microbiol. 5, 536-544. https://doi.org/10.1038/s41564-020-0695-z.

Dockery, D.M., Rowe, S.G., Murphy, M.A., Krzystolik, M.G. (2020). The Ocular Manifestations and Transmission of COVID-19; Recommendations for Prevention. J Emerg Med. S0736-4679(20)30398-X. doi: 10.1016/j.jemermed.2020.04.060.

European Centers for Disease Control and Prevention. Pneumonia Cases Possibly Associated with a Novel Coronavirus in Wuhan, China. Available online: https://www.ecdc.europa.eu/en/publicationsdata/pneumonia-cases-possibly-associated-novel-coronavirus-wuhan-china (accessed on 14 January 2020). 
FAO/WHO/OIE. (2004). Report of the WHO/FAO/OIE joint consultation on emerging zoonotic diseases, Food and Agriculture Organization of the United Nations (FAO), World Health Organization (WHO), and World Organisation for Animal Health (OIE), Document WHO/CDS/CPE/ZFK/2004.9, 65 pages.

Federation of European Heating, Ventilation and Air Conditioning Associations. COVID-19 guidance [Internet]. REHVA. April 3 [cited 2020 May 15]. Available from: https://www.rehva.eu/activities/covid-19guidance.

FEDIAF (2019). European facts and figures 2018. The European Pet Food Industry. FEDIAF, Bruxelles, Belgium, 10 pages. http://www.fediaf.org/images/FEDIAF_Facts__and_Figures_2018_ONLINE_final.pdf

Huang, K. (2020) Undiagnosed pneumonia - China (HU) (01): wildlife sales, market closed, RFI. ProMedmail. Archive Number 20200102.6866757.

Hubálek, Z. (2003) Emerging Human Infectious Diseases: Anthroponoses, Zoonoses, and Sapronoses. Emerg Infect Dis. 9(3), 403-404. doi: 10.3201/eid0903.020208.

Kaden, R. (2020). Early Phylogenetic Diversification of SARS-CoV-2: Determination of Variants and the Effect on Epidemiology, Immunology, and Diagnostics. J Clin Med 9(6), E1615. doi: 10.3390/jcm9061615.

Leroy, E.M., Ar Gouilh, M., Brugère-Picoux, J. (2020). The risk of SARS-CoV-2 transmission to pets and other wild and domestic animals strongly mandates a one-health strategy to control the COVID-19 pandemic. One Health 100133. doi: 10.1016/j.onehlt.2020.100133.

Li, F., Li, W., Farzan, M., Harrison, S.C. (2005). Structure of SARS coronavirus spike receptor-binding domain complexed with receptor. Science 309, 1864-1868. doi: 10.1126/science.1116480.

Li, W., Moore, M.J., Vasilieva, N., Sui, J., Wong, S.K., Berne, M.A., Somasundaran, M., Sullivan, J.L., Luzuriaga, K., Greenough, T.C., Choe H., Farzan, M. (2003). Angiotensin-converting Enzyme 2 Is a Functional Receptor for the SARS Coronavirus. Nature 426(6965), 450-454. doi: 10.1038/nature02145.

Li, F. (2012). Evidence for a common evolutionary origin of coronavirus spike protein receptor-binding subunits. J Virol 86, 2856-2858. doi: 10.1128/JVI.06882-11.

Lipsitch, M., Cohen, T., Cooper, B., Robins, J.M., Ma, S., James, L., Gopalakrishna, G., Chew, S.K., Tan, C.C., Samore, M.H., et al. (2003). Transmission dynamics and control of severe acute respiratory syndrome. Science 300, 1966-1970. doi: 10.1126/science.1086616.

Liu, P., Jiang, J.Z., Wan, X.F., Hua, Y., Li, L., Zhou, J., Wang, X., Hou, F., Chen, J., Zou, J., Chen, J. (2020). Are pangolins the intermediate host of the 2019 novel coronavirus (SARS-CoV-2)? PLoS Pathog.16(5), e1008421. doi: 10.1371/journal.ppat.1008421.

Mackenzie, J.S., Smith, D.W. (2020). COVID-19: a novel zoonotic disease caused by a coronavirus from China: what we know and what we don't? Microbiol Aust. MA20013. doi: 10.1071/MA20013 [Epub ahead of print].

McNamara, T., Richt, J.A., Glickman, L. (2020). A Critical Needs Assessment for Research in Companion Animals and Livestock Following the Pandemic of COVID-19 in Humans Vector-borne and zoonotic diseases 20(6), 393-405. doi: 10.1089/vbz.2020.2650

Oreshkova, N., Molenaar, R.J., Vreman, S., Harders, F., Oude Munnink, B.B., Hakze, R., Gerhards, N., Tolsma, P., Bouwstra, R., Sikkema, R., Tacken, M., de Rooij, M.M.T., Weesendorp, E., Engelsma, M., Bruschke, C., Smit, L.A.M., Koopmans, M., van der Poel, W.H.M., Stegeman, A. (2020). SARS-CoV2 infection in farmed mink, Netherlands, April 2020, Submitted. doi: 10.1101/2020.05.18.101493.

Park, J.E., Jung, S., Kim, A., Park J.E. (2018). MERS transmission and risk factors: a systematic review. BMC Public Health (2018) 18:574. https://doi.org/10.1186/s12889-018-5484-8. 
Park, M., Cook, A.R., Lim, J.T., Sun, Y., Dickens, B.L. (2020). A Systematic Review of COVID-19 Epidemiology Based on Current Evidence. J Clin Med. 9(4), 967. doi: 10.3390/jcm9040967.

Peng, L., Liu, J., Xu, W., Luo Q., Chen D., Lei Z., Huang Z., Li X., Deng K., Lin B., Gao Z. (2020). SARS-CoV-2 Can Be Detected in Urine, Blood, Anal Swabs, and Oropharyngeal Swabs Specimens. J Med Virol Accepted. doi: 10.1002/jmv.25936.

Qiao H., Xiang Z., Xian-Tao Z. (2020). COVID-19 Pandemic: Stop Panic Abandonment of Household Pets. J Travel Med. 27(3):taaa046. doi: 10.1093/jtm/taaa046.

Riley, S., Fraser, C., Donnelly, C.A., Ghani, A.C., Abu-Raddad, L.J., Hedley, A.J., Leung, G.M., Ho, L.M., Lam, T.H., Thach, T.Q., et al. (2003). Transmission dynamics of the etiological agent of SARS in Hong Kong: Impact of public health interventions. Science 300, 1961-1966. doi: 10.1126/science.1086478.

Riou, J., Althaus C., (2020). Pattern of early human-to-human transmission of Wuhan 2019 novel coronavirus (2019-nCoV), December 2019 to January 2020. Euro Surveill. 25(4) $\mathrm{pii}=2000058$. https://doi.org/10.2807/1560-7917.ES.2020.25.4.2000058.

Sailleau, C., Dumarest, M., Vanhomwegen, J., Delaplace, M., Caro, V., Kwasiborski, A., Hourdel, V., Chevaillier, P., Barbarino, A., Comtet, L., Pourquier, P., Klonjkowski, B., Manuguerra, J.C., Zientara, S., Lepoder, S. (2020). First detection and genome sequencing of SARS-CoV-2 in an infected cat in France. Transboundary and Emerging Diseases, Accepted.

Shi, J., Wen, Z., Zhong, G., Yang, H., Wang, C., Huang, B., Liu, R., He, X., Shuai, L., Sun, Z., Zhao, Y., Liu, P., Liang, L., Cui, P., Wang, J., Zhang, X., Guan, Y., Tan, W., Wu, G., Chen, H., Bu, Z. (2020). Susceptibility of ferrets, cats, dogs, and other domesticated animals to SARS-coronavirus 2. Science. eabb7015. doi: $10.1126 /$ science.abb7015.

Sit, T.H.C., Brackman, C.J., Ip, S.M., Tam, K.W.S., Law, P.Y.T., To, E.M.W., Yu, V.Y.T., Sims, L.D., Tsang, D.N.C., Chu, D.K.W., Perera, R.A.P.M., Poon, L.L.M, Peiris, M. (2020). Infection of dogs with SARS-CoV-2. Nature. doi: 10.1038/s41586-020-2334-5. [Online ahead of print].

Studer, N., Lutz, H , Saegerman, C., Gönczi, E., Meli, M.L., Boo, G., Hartmann, K., Hosie, M.J., Moestl, K., Tasker, S., Belák, S., Lloret, A., Boucraut-Baralon, C., Egberink, H.F., Pennisi, M.G., Truyen, U., Frymus, T., Thiry, E., Marsilio, F., Addie, D., Hochleithner, M., Tkalec, F., Vizi, Z., Brunetti, A., Georgiev, B., Ludwig-Begall, L., Tschuor, F., Mooney, C.T., Eliasson, C., Orro, J., Johansen, H., Juuti, K., Krampl, I., Kovalenko, K., Šengaut, J., Sobral, C., Borska, P., Kovaříková, S., Hofmann-Lehmann, R. (2019). PanEuropean Study on the Prevalence of the Feline Leukaemia Virus Infection - Reported by the European Advisory Board on Cat Diseases (ABCD Europe). Viruses 11(11):993. doi: 10.3390/v11110993.

Toma, B., Benet, J.-J., Dufour, B., Eloit, M., Moutou, F. \& Sanaa, M. (1991) Glossaire d'épidémiologie animale. Maisons-Alfort, France, Editions du Point Vétérinaire, 365 pages.

Van der Poel, W. (2020). COVID-19 detected on four mink farms. Communication of Wageningen University and Research, May 26, 2020. https://www.wur.nl/en/Research-Results/Research-Institutes/BioveterinaryResearch/show-bvr/COVID-19-detected-on-two-mink-farms.htm

van Doremalen, N., Bushmaker, T., Morris, D.H., Holbrook, M.G., Gamble, A., Williamson, B.N., Tamin, A., Harcourt, J.L., Thornburg, N.J., Gerber, S.I., Lloyd-Smith, J.O., de Wit, E., Munster, V.J. (2020). Aerosol and Surface Stability of SARS-CoV-2 as Compared with SARS-CoV-1. N Engl J Med. 382(16), 1564-1567. doi: 10.1056/NEJMc2004973.

Wang, W., Xu, Y., Gao, R., Lu, R., Han, K., Wu, G., Tan, W. (2020). Detection of SARS-CoV-2 in Different Types of Clinical Specimens. JAMA 323(18), 1843-1844. doi: 10.1001/jama.2020.3786.

Wei, J., Wei, W., Xiaofang, Z., Junjie, Z., Xingguang, L. (2020). Cross-species Transmission of the Newly Identified Coronavirus 2019-nCoV. J Med Virol. 92(4), 433-440. doi: 10.1002/jmv.25682. 
Woelfel, R., Corman, VM, Guggemos, W., Seilmaier, M., Zange, S., Mueller, M.A., Niemeyer, D., Vollmar, P., Rothe, C., Hoelscher, M., Bleicker, T., Bruenink, S., Schneider, J., Ehmann, R., Zwirglmaier, K., Drosten, C., Wendtner, C. (2020). Clinical presentation and virological assessment of hospitalized cases of coronavirus disease 2019 in a travel-associated transmission cluster. Preprint from medRxiv. doi: 10.1101/2020.03.05.20030502.

World Health Organization (2020a). Novel coronavirus (2019-nCoV). Situation Report 22. 11 February 2020. https://www.who.int/docs/default-source/coronaviruse/situation-reports/20200211-sitrep-22ncov.pdf?sfvrsn=fb6d49b1_2 (accessed 27 May 2020).

World Health Organization. (2020b). Modes of transmission of virus causing COVID-19: implications for IPC precaution recommendations. Scientific Brief from 29th March 2020. Available at: https://www.who.int/publications-detail/modes-of-transmission-of-virus-causing-covid-19-implicationsfor-ipc-precaution-recommendations (accessed 27 May 2020).

Wu, Y., Guo, C., Tang, L., Hong, Z., Zhou, J., Dong, X., Yin, H., Xiao, Q., Tang, Y., Qu, X., Kuang, L., Fang, X., Mishra, N., Lu, J., Shan, H., Jiang, G., Huang, X. (2020). Prolonged presence of SARS-CoV-2 viral RNA in faecal samples. Lancet Gastroenterol Hepatol. 5(5), 434-435. doi: 10.1016/S2468-1253(20)30083-2.

Wu, Z., McGoogan, J.M. (2020). Characteristics of and Important Lessons From the Coronavirus Disease 2019 (COVID-19) Outbreak in China: Summary of a Report of 72314 Cases From the Chinese Center for Disease Control and Prevention. JAMA. 2020 Feb 24. doi: 10.1001/jama.2020.2648.

Xiao, S., Li, Y., Wong, T., Hui, D.S.C. (2017). Role of fomites in SARS transmission during the largest hospital outbreak in Hong Kong. PLOS ONE 12(7), e0181558. doi: 10.1371/journal.pone.0181558.

Xu, L., Zhang, Y., Liu, Y., Chen, Z., Deng, H., Ma, Z., Wang, H., Hu, Z., Deng, F. (2009). Angiotensinconverting Enzyme 2 (ACE2) From Raccoon Dog Can Serve as an Efficient Receptor for the Spike Protein of Severe Acute Respiratory Syndrome Coronavirus. J Gen Virol 90(11), 2695-2703. doi: 10.1099/vir.0.0134900 .

Xu, X., Chen, P., Wang, J., Feng, J., Zhou, H., Li, X., Zhong, W., Hao, P. (2020). Evolution of the novel coronavirus from the ongoing Wuhan outbreak and modeling of its spike protein for risk of human transmission. Sci China Life Sci. 63(3), 457-460. doi: 10.1007/s11427-020-1637-5.

Young-Il, K., Seong-Gyu K., Se-Mi K., Eun-Ha K., Su-Jin P., Kwang-Min Y., Jae-Hyung C., Eun Ji K., Seunghun L., Mark Anthony B.C., Jihye U., Min-Suk S., Hye Won J., Van Dam L., Yeonjae K., Bum Sik C., Jun-Sun P., Ki-Hyun C., Suan-Sin F., Haryoung P., In-Pil M., Ok-Jun L., Richard J.W., Jae U.J., Young K.C. (2020). Infection and Rapid Transmission of SARS-CoV-2 in Ferrets. Cell Host Microbe 27(5), 704-709.e2. doi: 10.1016/j.chom.2020.03.023.

Yu, I.T.-S., Qiu, H., Tse, L.A., Wong, T.W. (2014). Severe Acute Respiratory Syndrome Beyond Amoy Gardens: Completing the Incomplete Legacy. Clin Infect Dis. 58(5), 683-686. doi: 10.1093/cid/cit797.

Zhang Q., Zhang H., Huang K., Yang Y., Hui X., Gao J., He X., Li C., Gong W., Zhang Y., Peng C., Gao X., Chen H., Zou Z., Shi Z., Jin M. (2020). SARS-CoV-2 neutralizing serum antibodies in cats: a serological investigation. bioRxiv preprint doi: https://doi.org/10.1101/2020.04.01.021196.

\section{Figure and appendixes caption}

Figure 1. Cumated frequency of pet-related and non pet-related COVID-19 publications, in PubMED [A] and ProMED-mail [B]

Legend: All-pets = all publications on COVID-19 without pet-related publications; Pets = exclusively petrelated publications on COVID-19. Numbers in italics represent the cumulated frequency for pet-related publications. 
Figure 2. Boxplot of the relative importance of the eight domains of COVID-19 drivers of emergence in pets $(\mathrm{N}=33$ experts $)$

Legend: The dashed line represents the median of the score distribution between the different experts; the solid lines below and above each rectangle represent, respectively, the first and the third quartiles; adjacent lines to the whiskers represent the limits of the $95 \%$ confidence interval; small circles represent outside values. The eight domains of drivers are: D1, pathogen/disease characteristics; D2, distance of outbreaks (spatialtemporal scales); D3, ability to monitor, treat and control the disease; D4, pets characteristics; D5, changes in climate conditions; D6, wildlife interface; D7, human activity; and D8, economic and trade activities.

Figure 3. Ranking of the overall weighted score for each potential COVID-19 driver of emergence in pets (Boxplot based on 33 experts)

Legend: X-Axis represents the drivers with the following codification: D1 to D8 refer to the eight domains of drivers and D1_1 to D8_5 refer to a specific driver (for the codification, see Table 1). Relation to the figure 4 was provided by the group named as respectively "very high", "high", "moderate" and "low" importance of the COVID-19 drivers of emergence in pets.

Figure 4. Aggregation of COVID-19 drivers of emergence in pets into four homogenous groups using a regression tree analysis

Legend: N, number; SD, standard deviation.

Figure 5. Sensitivity analysis according to the experts. The diagram visualizes any modification in the rank of COVID-19 drivers of emergence in pets induced by the withdrawal of a given expert's input

Legend: X, crosses represent the cut-off of more than five ranks between different steps. Withdrawal of experts have little effect on the ranking. X-Axis represents the expert considered: All, all experts; All-Exp1 to All-Exp33 all, experts minus the first (Exp1), the second (Exp2), until the last (Exp33). Y-Axis represents the ranking of the COVID-19 drivers of emergence in pets, which are presented inTable 1 (i.e. the domain code followed by driver code). Several drivers occupy the same rank because their overall weighted scores are similar.

Appendix S2 . Domains of each defined driver and their respective defined coefficients (scores)

Appendix S3 . Profile of experts involved in the elicitation of knowledge ( $\mathrm{N}=33)$

Appendix S4. Guidance letter for the expert elicitation

\section{Hosted file}

Table1.docx available at https://authorea.com/users/331134/articles/457846-first-expertelicitation-of-knowledge-on-drivers-of-emergence-of-the-covid-19-in-pets 


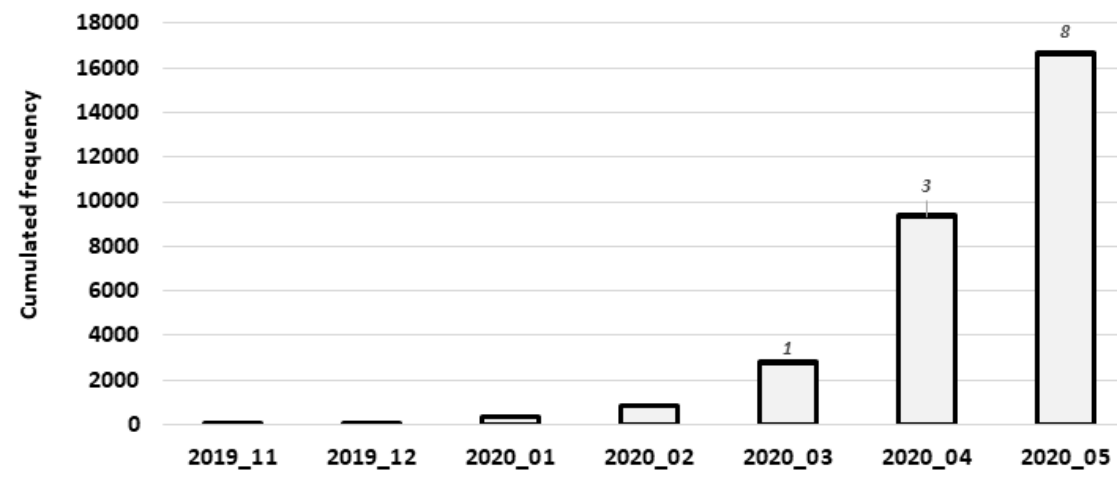

[B]
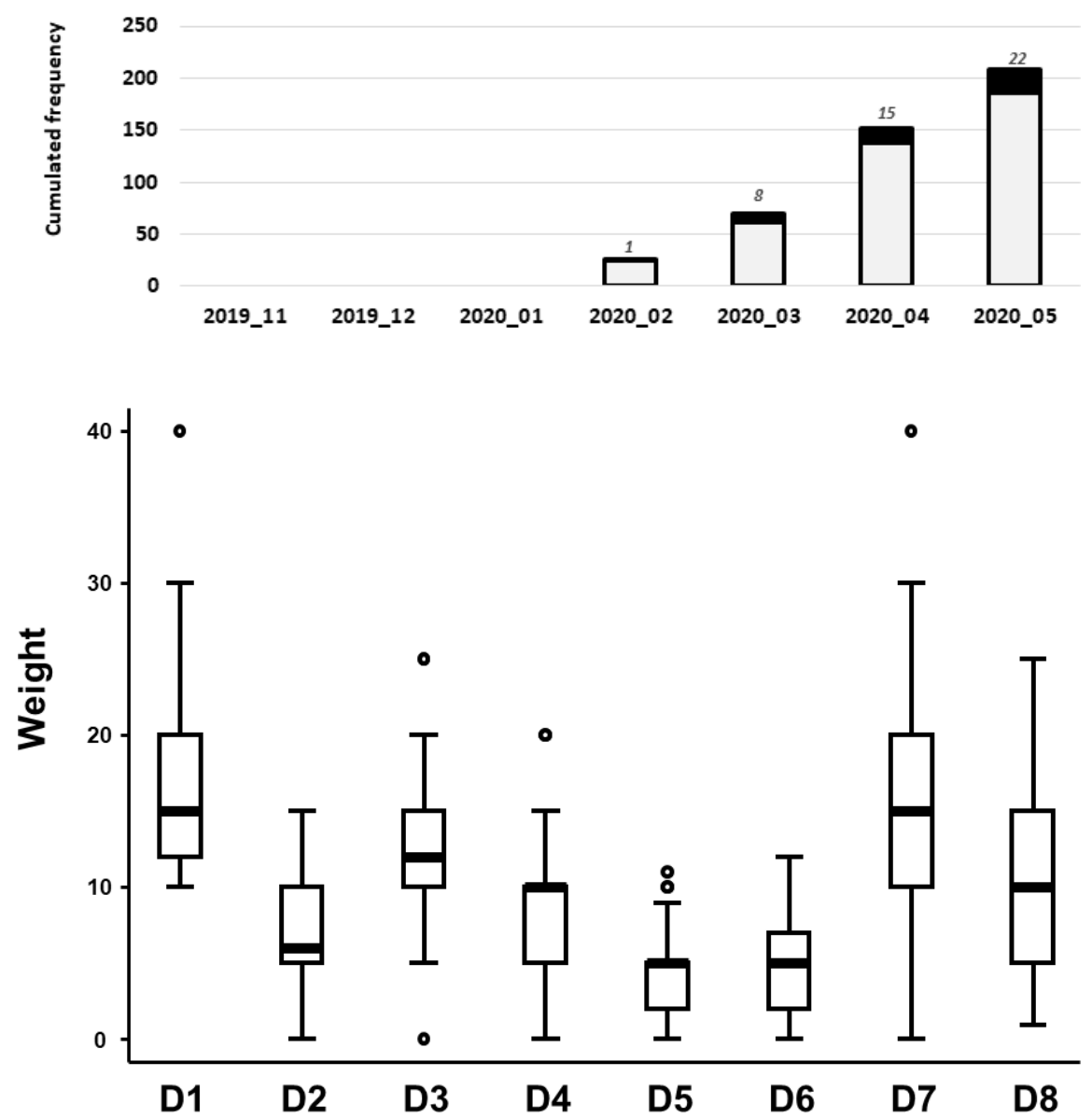

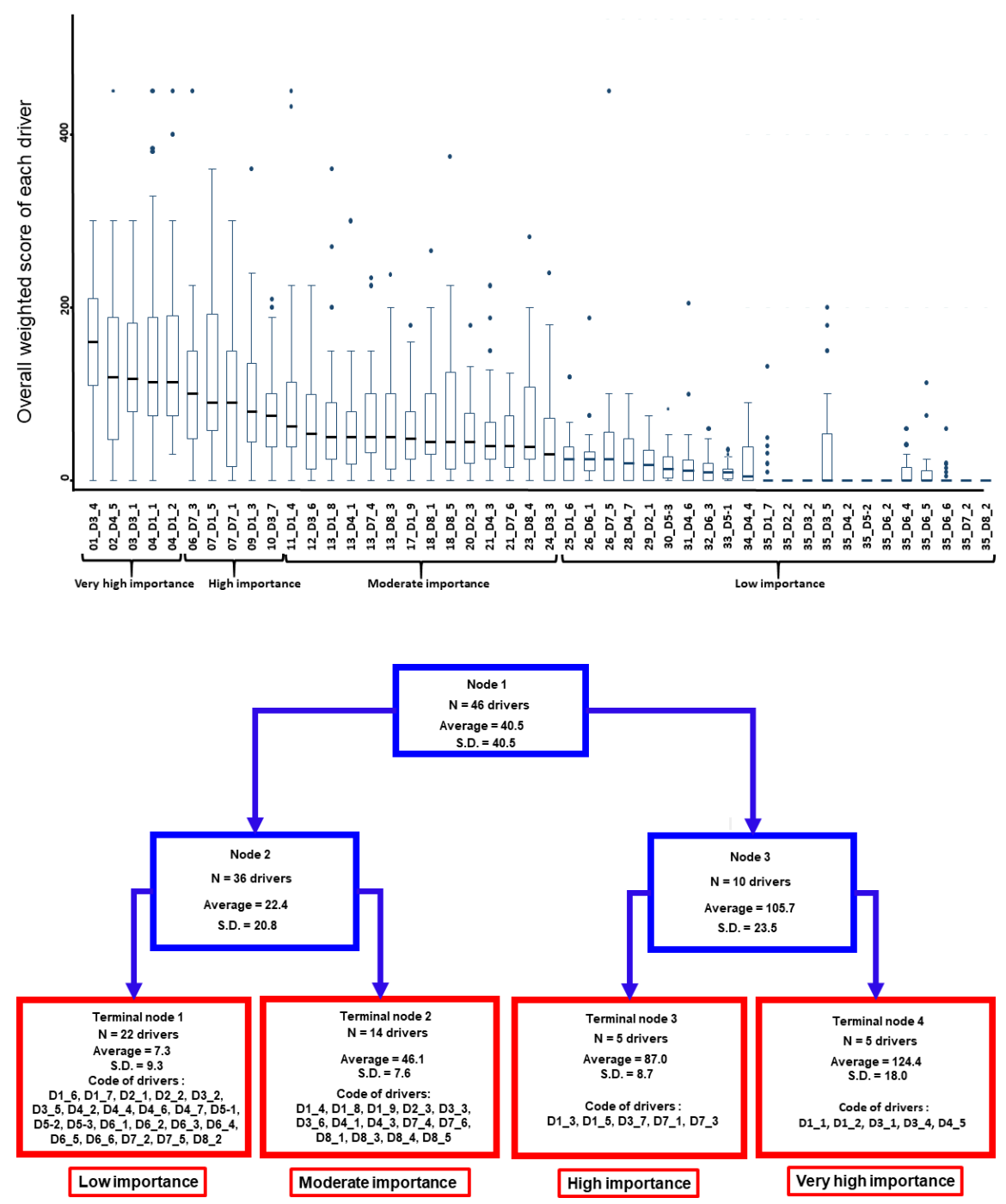


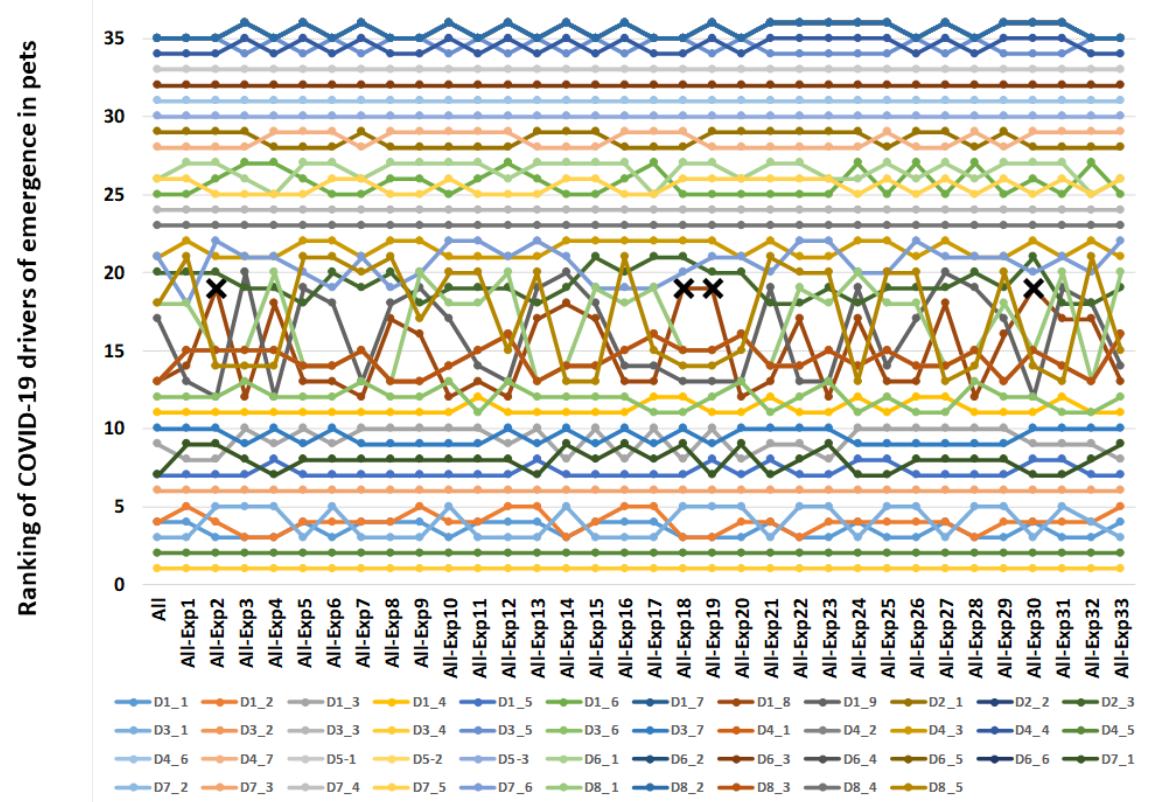

